\title{
EFEITO DA COLESTASE NOS ASPECTOS FUNCIONAIS E MORFOLÓGICOS RENAIS APÓS NEFRECTOMIA
}

\author{
Daniel Xavier lima*, Andy Petroianu, Kelly Cristine de Lacerda Rodrigues, Paulo Guilherme de Oliveira Salles
}

Trabalho realizado na Faculdade de Medicina da Universidade Federal de Minas Gerais, Belo Horizonte, MG

\author{
*Correspondência: \\ Rua. Engenheiro Carlos \\ Antonini, 136, apto 201 \\ Bairro São Lucas \\ Belo Horizonte, Minas \\ Gerais \\ Fone/FAX: (31) 32811090
}

\begin{abstract}
RESUMO
OBjetivos. O crescimento de um rim em resposta à perda do outro rim recebe o nome de hipertrofia renal compensatória. Entretanto, os mecanismos que regulam esse processo ainda não foram esclarecidos. Neste estudo, avaliaram-se os efeitos da icterícia obstrutiva na morfologia e na função do rim remanescente após nefrectomia unilateral. Métodos. Foram estudados 40 ratos Wistar $(250 \mathrm{~g}-300 \mathrm{~g})$, distribuídos nos seguintes grupos: Grupo I - operaçãa simulada; Grupo 2 - nefrectomia direita; Grupo 3 - ligadura do ducto biliar; Grupo 4 - ligadura do ducto biliar e nefrectomia direita. Os animais foram mortos após 20 dias, quando foi collido sangue para exames laboratoriais e feita a retirada dos rins e do fígado. Os rins foram pesados para avaliação do crescimento compensatório. Rins e figado foram estudados histologicamente por microscopia óptica.

Resultados. Não houve diferença no aumento do peso renal relativo entre os animais dos Grupos 2 e 4 ( $p=0,4)$. Os animais submetidos à ligadura do ducto biliar isoladamente (Grupo 3) apresentaram maior peso renal relativo quando comparados com os animais submetidos à operação simulada (Grupo I) $(p=0,01 \mathrm{I})$. As alterações histológicas encontradas foram dilatação capilar da camada medular nos rins hipertrofiados e modificações típicas de colestase nos fíaados dos animais ictéricos. Cirrose foi encontrada apenas nos animais submetidos à nefrectomia.
\end{abstract}

Conclusão. O peso e a função do rim remanescente após nefrectomia unilateral não são afetados pela icterícia obstrutiva.

UntTeRMOS: Cirurgia. Colestase. Nefrectomia. Hipertrofia. Morfologia.

\section{INTRODUÇÃO}

O crescimento de um rim em resposta à perda do outro rim recebe o nome de hipertrofia compensatória. Estudos experimentais sobre a hipertrofia compensatória após nefrectomia unilateral vêm sendo conduzidos desde o século XIX. Inicialmente, acreditava-se que o crescimento compensatório do rim era devido exclusivamente ao aumento do tamanho das células (hipertrofia). Essa teoria teve início nas investigações de Arataki', que chegou à conclusão de que néfrons maduros podem crescer, mas não aumentar seu número.

Atualmente, sabe-se que o aumento das dimensões renais após a perda do rim contralateral ocorre tanto devido ao crescimento das células, quanto à proliferação celular (hiperplasia), mesmo em animais adultos ${ }^{2,3,4}$. Entretanto, o termo hipertrofia ainda é usado para designar todo o processo, uma vez que o fenômeno predominante é o aumento do tamanho e do conteúdo protéico das células já existentes, o que leva ao aumento do peso renal $2,3,5$.

O peso do rim tende a ser uniforme entre os indivíduos da mesma espécie, sexo e idade, quando medido proporcionalmente ao peso corporal $^{6}$. Por ser um parâmetro confiável e simples de avaliar, o peso renal proporcional ao peso corpóreo é utilizado em estudos experimentais sobre hipertrofia compensatória ${ }^{2,4,6,7}$.

A conexão funcional entre fígado e rins já foi descrita em diversos trabalhos clínicos e experimentais. A regulação hepática da função renal parece envolver um "reflexo hepatorrenal" e um "fator diurético" originado no fígado, denominado glomerulopressina ${ }^{8}$. A conexão funcional entre fígado e rins também pode ser vista nas alterações desencadeadas por colestase. As modificações adaptativas à icterícia obstrutiva ocorrem de maneira coordenada no figado e nos rins, que constituem uma via alternativa para a excreção de sais biliares?

A icterícia obstrutiva acompanha-se de elevada morbidade e mortalidade, especialmente para pacientes cirúrgicos ${ }^{10}$. Experimentalmente, a colestase pode ser produzida pela ligadura do ducto biliopancreático, com desenvolvimento de hepatomegalia e alterações na histoarquitetura hepática, incluindo septos de fibroses perivenular e periporta, colangite e hiperplasia de ductos biliares". Embora haja estudos sobre a função do fígado e dos rins em presença de icterícia, ainda não se encontram pesquisas sobre a hipertrofia renal compensatória nessas circunstâncias.

O objetivo do presente trabalho foi avaliar o efeito da icterícia obstrutiva na morfologia e na função do rim remanescente após nefrectomia.

\section{Métodos}

Este trabalho foi realizado no Laboratório de Pesquisa do Departamento de Cirurgia da Faculdade de Medicina da Universidade Federal de Minas Gerais (UFMG) e foi aprovado pelo Comitê de Ética em Experimentação Animal da UFMG, protocolado sob o número 025/05.

Foram estudados 40 ratos (Rattus norvegicus) da raça Wistar, sendo 20 machos e 20 fêmeas, oriundos do Biotério do Instituto de Ciências 
Biológicas da UFMG, com idade entre dois e três meses de vida. O peso médio das fêmeas foi $216,2 \mathrm{~g} \pm 37, \mathrm{I} \mathrm{g}$ (média \pm desvio padrão) e o dos machos foi $287,2 \mathrm{~g} \pm 53,6 \mathrm{~g}$. Os animais permaneceram alojados em gaiolas próprias no Biotério da Faculdade de Medicina da UFMG, com, no máximo, cinco ratos do mesmo sexo por gaiola, tendo livre acesso à ração balanceada padrão para ratos e água. Todos os animais receberam cuidados de acordo com as recomendações do Comitê de Ética em Experimentação Animal da UFMG (http://www.ưmg.br/bioetica/cetea).

A distribuição dos animais foi feita aleatoriamente em quatro grupos constituídos por cinco machos e cinco fêmeas: Grupo | - operação simulada; Grupo 2 - nefrectomia direita; Grupo 3 - ligadura do ducto biliar; Grupo 4 - ligadura do ducto biliar e nefrectomia direita.

Após jejum de 12 horas para sólidos e líquidos, os animais foram anestesiados com cloridrato de xilasina a 2\% (Rompun ${ }^{\circledR}$, Bayer, São Paulo, Brasil) na dose de $15 \mathrm{mg} / \mathrm{kg}$ e com cloridrato de quetamina a $5 \%$ (Ketalar ${ }^{\circledR}$, Pfizer, Guarulhos, Brasil) na dose de $90 \mathrm{mg} / \mathrm{kg}$, por via intraperitoneal e aquecidos com lâmpada elétrica. Após tonsura, era realizada antisepsia com polivinilpirrolidonaiodo (Asteriodine ${ }^{\circledR}$, Aster, Sorocaba, Brasil) e incisão abdominal mediana xifopúbica.

Para a operação simulada, era feita a manipulação dos rins e do hilo hepático, seguida do fechamento do abdome em dois planos, com fio de mononálon 4-0 (Superlon®, Lajeado, Brasil). Para interrupção do fluxo de bile pelo ducto biliar comum, foi realizada sua secção entre ligaduras com fio seda 5-0 (Biosut $₫$, Belo Horizonte, Brasil), a cerca de um centímetro de sua entrada no duodeno.

O rim direito foi escolhido para servir como controle para o crescimento renal compensatório. Para a nefrectomia direita, o rim foi exposto pela mesma incisão. Seus vasos (artéria e veia) e o ureter foram dissecados e ligados em separado com fio seda 4-0 (Biosut $®$, Belo Horizonte, Brasil), sendo depois seccionados para a remoção do órgão, preservando a glândula adrenal. Os rins foram pesados em balança analítica digital (Sartorius ${ }^{\circledR}$ BP 61, Bradford, EUA) e armazenados em frasco contendo solução de formol a $10 \%\left(\mathrm{CH}_{2} \mathrm{O}\right)$. Antes de serem pesados, a gordura perirrenal era cuidadosamente retirada, mantendo a cápsula renal íntegra. A artéria, a veia e o ureter eram seccionados junto ao hilo renal.

Ao final do procedimento, o abdome foi fechado em dois planos, com fio de mononáilon 4-0 (Superlon ${ }^{\circledR}$, Lajeado, Brasil). No período pós-operatório, os animais foram acompanhados diariamente no biotério, tendo recebido água e ração à vontade.

Decorrido o período estabelecido para acompanhamento dos animais, cada rato foi novamente anestesiado e submetido à laparotomia mediana xifopúbica. Por punção na veia cava abdominal, coletou-se sangue em sistema a vácuo (Vacuntainer ${ }^{\circledR}$, Becton Dickinson, Brasil) para análise bioquímica.

Um fragmento do lobo direito do fígado foi removido e armazenado em frasco contendo solução de formol a $10 \%$. Os rins foram pesados em balança analítica digital, logo após sua remoção cirúrgica. Em seguida, eles foram armazenados em solução de formol a $10 \%$. A veia cava abdominal foi seccionada para a morte dos animais por exsangüinação.

O sangue de cada animal foi coletado em dois tubos estéreis (Vacuntainer ${ }^{\circledR}$, Becton Dickinson, Brasil), sendo um para exames hematológicos (com anticoagulante) e o outro para análise bioquímica (sem anticoagulante, mas com gel separador). Os tubos foram revestidos com papel alumínio, para proteção da luz e centrifugados a 3000 rpm por 10 minutos.

As análises foram realizadas no setor de Bioquímica do Laboratório Central do Hospital das Clínicas da UFMG. Os exames hematológicos realizados foram a contagem de leucócitos e de plaquetas, dosagem de hemoglobina e cálculo do hematócrito (contador hematológico Abbott Cell-Dyn $\left.{ }^{\circledR} 3200\right)$. Os exames bioquímicos foram a dosagem de uréia, creatinina, aminotransferases, bilirrubinas, albumina, globulina e fosfatase alcalina. Para estudo histológico, as amostras foram submetidas a processamento habitual e foram corados por hematoxilina e eosina (HE), PAS (ácido periódico de Schiff), tricrômico de Gomori, coloração pela prata e retículo.

A dilatação dos capilares medulares foi avaliada pela comparação do diâmetro de seu lume com o das hemácias, da seguinte forma: normal (presença de capilares com 7 a 9 mm de diâmetro, permitindo a passagem de apenas uma hemácia); aumento pequeno (capilares com lume aumentado, permitindo a passagem simultânea de duas hemácias); aumento grande (capilares com lume maior, permitindo a passagem simultânea de mais de duas hemácias).

As presenças de glomerulosclerose e de fibrose tubular intersticial foram também avaliadas por microscopia óptica e registradas como presentes ou ausentes. Ao exame histológico do fígado, foram procuradas as seguintes alterações em cada animal: proliferação periporta de ductos biliares; proliferação periférica de ductos biliares; figuras de mitose nos hepatócitos; áreas de necrose; fibrose periductal concêntrica; presença de cirrose.

Nas comparações entre os grupos, foi utilizado o teste nãoparamétrico de Mann-Whitney, tomando-se o Grupo I como referência para os demais. Na comparação do peso inicial com o peso final dos animais, foi utilizado o teste de $\mathrm{t}$ pareado. $\mathrm{Na}$ análise de variáveis categóricas, foi usado o teste de Fisher. Em todas as análises, um valor de $p<0,05$ indicava que os grupos eram diferentes estatisticamente.

\section{Resultados}

Em todos os animais operados, o ato cirúrgico transcorreu sem anormalidades. À laparotomia, não foram vistas alterações morfológicas hepáticas ou renais que excluíssem o rato da pesquisa. Ainda nas primeiras horas após os procedimentos, os animais recuperaram-se espontaneamente.

Os animais dos Grupos I e 2 não apresentaram alterações em sua aparência ou em seus hábitos fisiológicos. Entretanto, todos os animais que foram submetidos à ligadura e secção do ducto biliar tornaram-se ictéricos, com pigmentaçãa amarelada da pele e da mucosa, além de colúria e hipocolia fecal. Apenas um rato (Grupo 4) morreu no pósoperatório, antes do final do perído de observação estipulado.

A média de peso proporcional dos rins direito e esquerdo não foi diferente entre os animais do Grupo Controle e os submetidos à ligadura biliar (Grupo 3). Houve diferença apenas entre os rins dos animais que foram submetidos à nefrectomia direita e à nefrectomia direita associada com ligadura do ducto biliar (Grupos 2 e 4) (Tabela I).

Os animais submetidos à ligadura do ducto biliar isoladamente (Grupo 3) apresentaram maior peso renal relativo (peso do rim / peso corporal) quando comparados com os animais submetidos à operação 


\begin{tabular}{|c|c|c|c|c|c|c|}
\hline & \multirow{2}{*}{ Procedimento cirúrgico } & \multirow{2}{*}{ Observação (dias) } & \multirow{6}{*}{$\begin{array}{c}\frac{\mathbf{n}}{10} \\
10 \\
10 \\
9\end{array}$} & \multirow{2}{*}{ Rim direito } & \multirow{2}{*}{$\begin{array}{l}\text { ripóreo } \\
\text { Rim esquerdo }\end{array}$} & \\
\hline Grupo & & & & & & $\mathrm{p}$ \\
\hline I & Operação simulada & 20 & & $\overline{0,38 \pm 0,01}$ & $0,32 \pm 0,11$ & 0,143 \\
\hline 2 & Nefrectomia direta & 20 & & $0,41 \pm 0,03$ & $0,50 \pm 0,07$ & $0,018 *$ \\
\hline 3 & Ligadura do ducto billar & 20 & & $0,44 \pm 0,07$ & $0,43 \pm 0,07$ & 0,650 \\
\hline 4 & Ligadura do ducto biliar + Nefrectomia direita & 20 & & $0,42 \pm 0,05$ & $0,54 \pm 0,07$ & $0,0005 *$ \\
\hline
\end{tabular}

Valores expressos em média \pm desvio padrão da média

Teste Mann-Whitney

* Houve diferença entre as médias dos pesos renais do mesmo grupo

\begin{tabular}{|c|c|c|c|c|c|c|c|c|}
\hline \multirow[t]{2}{*}{ Grupo } & \multirow[t]{2}{*}{ Procedimento cirúrgico } & \multirow[t]{2}{*}{$\mathrm{n}$} & \multicolumn{6}{|c|}{ Alterações histológicas } \\
\hline & & & $\bar{A}$ & B & C & D & $\mathbf{E}$ & $\mathbf{F}$ \\
\hline 2 & Nefrectomia direita & 10 & - & - & - & - & - & - \\
\hline 3 & Ligadura do ducto biliar & 10 & 0 & 9 & - & 2 & - & - \\
\hline 4 & Ligadura do ducto biliar + Nefrectomia direita & 9 & 8 & 8 & - & | & - & 7 \\
\hline
\end{tabular}

$\mathrm{A}=$ Proliferação periporta de ductos biliares

$B=$ Proliferação periférica de ductos biliares

$C=$ Figuras de mitose nos hepatócitos

$\mathrm{D}=$ Áreas de necrose

$E=$ Fibrose periductal concêntrica

$F=$ Cirrose

simulada (Grupo I) $(p=0,0 \mid$ I) . Essa diferença não ocorreu quando se comparou o peso relativo do rim direito dos animais do Grupo I com os do Grupo 2 ( $p=0,123)$.

Nos animais submetidos à nefrectomia direita (Grupos 2 e 4), ao considerar o peso do rim direito como referência inicial e o peso do rim esquerdo como referência final do processo de hipertrofia compensatória, não houve diferença na proporção peso do rim / peso do animal $(p=0,4)$.

Os rins do Grupo Controle não apresentaram alterações histológicas. Não foram observadas glomeruloesclerose ou fibrose tubulointersticial nos rins analisados. Dilatação capilar medular foi encontrada no rim esquerdo de todos os grupos em que foi feita a nefrectomia direita prévia, em intensidades variáveis. Não houve diferença na freqüência desse achado entre os grupos 2 e 4 $(p=0,3416)$ e entre os grupos 2 e $3(p=0,3698)$.

Não foram encontradas alterações histológicas nos fígados dos ratos do Grupo Controle. Alterações hepáticas ocorreram em todos os animais que foram submetidos a ligadura do ducto biliar, tendo predominado a proliferação de ductos biliares (Grupos 3 e 4) (Tabela 2). Foi identificada cirrose hepática apenas nos animais submetidos à nefrectomia associada à ligadura do ducto biliar (Grupo 4).

Os valores de bilirrubina direta, bilirrubina indireta, aspartatoaminotransferase (ASAT) e alaninaminotransferase (ALAT) foram maiores em todos os grupos nos quais foi feita a ligadura do ducto biliar ( $p<0,05)$, quando comparados com o Grupo I (controle). A elevação de bilirrubinas ocorreu principalmente pela fração direta.

Os níveis de bilirrubina direta foram maiores nos animais submetidos à ligadura do ducto biliar associada à nefrectomia direita (Grupo 4) do que naqueles com ligadura isolada do ducto biliar (Grupo 3) $(p=0,0266)$. Os valores de uréia foram menores no Grupo I do que em todos os outros grupos $(p<0,05)$. Nos grupos em que foi realizada nefrectomia, os valores de creatinina sérica foram superiores aos do Grupo I. Não houve diferença nos níveis de creatinina entre os Grupos 2 e $4(p=0,0545)$.

Nos animais submetidos à nefrectomia direita associada à ligadura do ducto biliar (Grupo 4), os níveis de albumina sérica foram inferiores aos do Grupo Controle $(p=0,003$ I). A relação albumina/globulina foi menor nos ratos submetidos à ligadura do ducto biliar e ligadura do ducto biliar associada à nefrectomia direita (Grupo 4) do que no Grupo I ( $p=0,003$ ).

\section{Discussão}

Este trabalho faz parte de uma linha de pesquisa sobre a fisiopatologia da icterícia obstrutiva ${ }^{I-16}$ e investigou o efeito da colestase no processo de hipertrofia renal compensatória.

A escolha do rato como modelo experimental teve por base estudos prévios que mostraram ser esse um bom animal para estudo da hipertrofia renal compensatória ${ }^{17}$ e de fenômenos da icterícia obstrutiva ${ }^{11-16}$.

$\mathrm{Na}$ casuística desta investigação, a secção entre ligaduras do ducto biliopancreático ocasionou colestase e hiperbilirrubinemia, com predomínio da fração direta, além de aumento nas aminotransferases e fosfatase alcalina séricas, bem como redução na relação albumina/ globulina. Tais alterações são compatíveis com a obstrução da via biliar e a disfunção hepática associada. Essa obstrução levou a alterações histológicas hepáticas em todos os animais ictéricos. Dentre as alterações encontradas, predominou a proliferação de ductos biliares, desorganizando a histoarquitetura hepática. Em estudo anterior, alterações semelhantes foram observadas com a mesma técnica". 
Deve-se ressaltar que a cirrose hepática foi identificada apenas nos fígados de animais submetidos à obstrução da via biliar associada à nefrectomia. Tais achados sugerem que a nefrectomia tenha intensificado as modificações na histologia hepática desencadeadas pela colestase. A disfunção hepática pode acarretar modificações na filtração e levar à disfunção renal91.18. Cabe ressaltar que existem evidências experimentais de que o figado exerce função reguladora da função renal| .

Uma provável explicação para esse achado pode estar nos níveis mais elevados de bilirrubina direta, observados no Grupo 4, quando comparados com o Grupo 3. Sabe-se que os rins constituem uma rota alternativa para a eliminação do excesso de sais biliares em presença de icterícia obstrutiva9. Isso ocorre por meio do aumento da filtração glomerular, redução na absorção e por excreção tubular ativa de bilirrubina nos rins. $\mathrm{Na}$ ausência de um dos rins, é possível que essa via de excreção tenha se tornado insuficiente para eliminar a sobrecarga de sais biliares, fazendo com que níveis mais elevados de bilirrubina permaneçam na circulação.

$\mathrm{O}$ aumento do peso do rim remanescente ocorreu em proporções semelhantes nos ratos com ligadura do ducto biliar e nefrectomia direita e naqueles submetidos apenas à nefrectomia. Portanto, a icterícia não influenciou no crescimento do rim remanescente. Todavia, é possível que a icterícia obstrutiva tenha influenciado esse processo, uma vez que o peso proporcional dos rins dos animais submetidos apenas à ligadura do ducto biliar foi elevado. Crianças com atresia de via biliar podem apresentar nefromegalia, que é reversível após transplante hepático ${ }^{19,20}$. É provável que o fator de crescimento de hepatócitos seja a substância mitogênica responsável pelo início do processo de hipertrofia renal.

\section{ConClusão}

O aumento do peso e as mudanças na função do rim remanescente que ocorrem na hipertrofia renal compensatória, desencadeada pela nefrectomia unilateral, não são alterados pela icterícia obstrutiva.

\section{Conflito de interesse: não há}

\section{SUMMARY}

\section{EfFEct OF CHOLESTASIS ON RENAL MORPHOLOGICAL AND FUNCTIONAL ASPECTS AFTER NEPHRECTOMY}

OBEECTNE. The removal of one kidney results in a compensatory growth of the remnant kidney. However, the mechanism that underlies this hypertrophic response is not understood. In this study we assessed the influence of obstructive jaundice on renal morphology and function after unilateral nephrectomy.

METHODS. Forty Wistar rats (250-300 g) were randomly divided into four groups: Group I - sham operation, Group 2 - right nephrectomy, Group 3 - common bile duct ligation, Group 4 - common bile duct ligation and rightnephrectomy. After 20 days, blood was collectedfor biochemical studies and the animals were killed. Their kidneys and livers were removed and weighed. Histological evaluation of both organs was carried out.

RESULTS. No difference in the kidney/body weightratio was observedfor animals undergoing right nephrectomy (Groups 2 and 4) $(p=0.4)$. Animals submitted to bile duct ligation only (Group 3) presented a higher kidney/body weight ratio than animals submitted to shamoperation (Group 1) $(p=0.011)$. Vasodilatation was identified in the medulla of the hypertrophied kidneys and histological alterations were found in the livers of the jaundiced animals. Cirrhosis occurred only in nephrectomized rats.

CONCLUSION. Cholestasis does not affect the weight, function or the compensatory renal growth of the remnant kidney after unilateral nephrectomy. [Rev Assoc Med Bras 2008; 54(6): 513-6]

KEY wORDS: Surgery. Cholestasis. Nephrectomy. Hypertrophy. Morphology.

\section{REFERÊNCIAS}

I. Arataki M. Experimental researches on the compensatory enlargement of the surviving kidney after unilateral nephrectomy. Am J Anat 1926; 36: 437-55.

2. Johnson HA, Vera Roman JM. Compensatory renal enlargement. Am J Pathol 1966; 49: I- I3.

3. Threlfall G, Taylor DM, Buck AT. Studies of the changes in growth and DNA synthesis in the rat kidney during experimentally induced renal hypertrophy. Am | Pathol 1967; 50: |-|4.

4. Seyer-Hansen K, Gundersen HJ, Osterby R. Stereology of the rat kidney during compensatory renal hypertrophy. Acta Pathol Microbiol Immunol Scand 1985; 93: 9-12

5. Fine LG. The biology of renal hypertrophy. Kidney Int 1986; 29: 619-34.

6. Wesson LG, Compensatory growth and other growth responses of the kidney. Nephron 1989; 51 : 149-84

7. Flyvbjerg A, Schrijvers BF, De Vriese AS, Tilton RG, Rasch R. Compensatory glomerular growth after unilateral nephrectomy is VEGF dependent. Am J Physiol Endocrinol Metab 2002; 283: E362-6.

8. Lang F, Tschernko E, Haussinger D. Hepatic regulation of renal function. Exp Physiol 1992; 77: 663-73.

9. Denk GU, Cai SY, Chen WS, Lin A, Soroka CJ, Boyer JL. A comparison of gene expression in mouse liver and kidney in obstructive cholestasis utilizing high-density oligonucleotide microarray technology. World J Gastroenterol 2006; 12: 2536-48.

10. O'Connor MJ. Mechanical biliary obstruction. Am Surg 1985; 5 I : 245-5 I.

II. Vasconcellos LS, Alberti LR, Romeiro JR, Petroianu A. Alterações da morfologia hepática após ligadura do ducto biliopancreático em ratos. An Fac Med Univ Fed Pernamb Recife 2005; 50: 81-7.

12. Duval-Araújo I, Okawa RY, Alves-Silva A, Petroianu A. Fatores desencadeantes da insuficiência renal aguda no pós-operatório. An Paul Med Cir 1992; I19: 25-32.

13. Duval-Araújo I, Petroianu A, Oliveira-Neto JE, Sabino LO. Endotoxininduced enteric hypomotility in jaundiced loops in vitro. Braz J Med Biol Res 1996; 29: 995-9.

14. Duval-Araújo I, Alves-Silva A, Okawa RY, Petroianu A. Alterações histológicas em fígado de ratos ictéricos após uso de sais biliares exógenos por via oral. Rev Bras Cir 1997; 87: 79-81.

15. Arantes VN, Okawa RY, Pereyra WJF, Barbosa AJA, Petroianu A. Influence of obstructive jaundice on wound and jejunal anastomosis healing in rats. Rev Col Bras Cir 1999; 26: 269-73.

16. Sousa VRA, Sousa AA, Petroianu A, Simal CJR, Barbosa AJA. Influence of acute renal failure on the mononuclear phagocytic system. Braz J Med Biol Res 2001; 34: I 169-74

17. Haramati A, Lumpkin MD, Mulroney SE. Early increase in pulsatile growth hormone release after unilateral nephrectomy in adult rats. Am J Physiol 1994; 266: F628-32

18. Cárdenas A. Hepatorenal syndrome: a dreaded complication of end-stage liver disease. Am J Gastroenterol 2005; 100: 460-7.

19. Tsau YK, Jou ST, Ni YH. Nephromegaly relates to hepatocyte growth factor dysregulation in biliary atresia. Pediatr Nephrol 2002; 17: 554-9.

20. Cheng CH, Tsau YK, Tsai, IJ. Kidney volume and plasma hepatocyte growth factor-transforming growth factor beta I ratio among children with biliary atresia before and after liver transplantation. Am J Kidney Dis 2005; 46: 830-6.

Artigo recebido: 28/1 1/07

Aceito para publicação: 20/04/08 